\title{
The ionospheric response to flux transfer events: the first few minutes
}

\author{
A. S. Rodger, M. Pinnock \\ British Antarctic Survey, Natural Environment Research Council, Madingley Road, Cambridge, CB3 0ET, UK \\ Received: 20 December 1995 / Revised: 6 January 1997 / Accepted 13 January 1997
}

\begin{abstract}
We utilise high-time resolution measurements from the PACE HF radar at Halley, Antarctica to explore the evolution of the ionospheric response during the first few minutes after enhanced reconnection occurs at the magnetopause. We show that the plasma velocity increases associated with flux transfer events (FTEs) occur first $\sim 100-200 \mathrm{~km}$ equatorward of the region to which magnetosheath (cusp) precipitation maps to the ionosphere. We suggest that these velocity variations start near the ionospheric footprint of the boundary between open and closed magnetic field lines. We show that these velocity variations have rise times $\sim 100 \mathrm{~s}$ and fall times of $\sim 10 \mathrm{~s}$. When these velocity transients reach the latitude of the cusp precipitation, sometimes the equatorward boundary of the precipitation begins to move equatorward, the expected and previously reported ionospheric signature of enhanced reconnection. A hypothesis is proposed to explain the velocity variations. It involves the rapid outflow of magnetospheric electrons into the magnetosheath along the most recently reconnected field lines. Several predictions are made arising from the proposed explanation which could be tested with ground-based and space-based observations.
\end{abstract}

\section{Introduction}

The concept of reconnection at the dayside magnetopause, introduced over 30 years ago (Dungey, 1961), has been very successful in describing many of the largescale features of the high-latitude ionosphere and magnetosphere. The influence of the interplanetary magnetic field (IMF) on the magnitude and direction

Correspondence to: A. S. Rodger of high-latitude ionospheric convection patterns, and the explanation of the cusp ion plume are two notable achievements. However, many aspects of reconnection are still poorly understood despite the fact that it is a process of paramount importance in determining the structure, dynamics and variability of the high-latitude ionosphere-magnetosphere system. There remains major controversy whether reconnection occurs in a quasisteady manner (Newell and Sibeck, 1993) or as a transient phenomenon at a single site on the magnetopause (e.g. Lockwood et al., 1994), or indeed whether reconnection occurs simultaneously at multiple sites on the magnetopause (Kan, 1988; Pinnock et al., 1995). For any set of prevailing solar wind conditions, there is no accurate quantitative model to determine when, where or for how long reconnection occurs on the magnetopause. Therefore it is impossible to determine accurately the energy transferred into near-geospace from the solar wind, and thus predict with any degree of confidence the consequences of reconnection on the closely-coupled magnetosphere-ionosphere system.

There is an increasing body of evidence that suggests that transient reconnection events, commonly termed flux transfer events (FTEs), can be the major source of energy transfer from the solar wind into the magnetosphere. Initially, FTEs were studied using data from single or dual spacecraft in orbits that were not ideal for understanding the physics involved (e.g. Russell and Elphic, 1979; Rijnbeck et al., 1984). The search for the ionospheric signatures of FTEs has increased markedly in the last decade. The first observations were made using the STARE VHF radar system (Goertz et al., 1985), and thereafter signatures using incoherent scatter radar (Lockwood et al., 1990, 1993); optical (Sandholt et al., 1990); magnetometer (Lanzerotti et al., 1990) and HF radar data (Pinnock et al., 1991, 1993) followed. With the further development of the HF radar systems (Greenwald et al., 1995), measurements of unparalleled spatial and temporal resolution are now possible (Pinnock et al., 1995), offering new insight into the ionospheric signatures of FTEs. 
In this work, we shall exploit further the data set described by Pinnock et al., (1995). We suggest that our data bring into question the existing concepts for describing the first few minutes of the ionospheric response to flux transfer events.

\section{The conventional picture of ionospheric response to a flux transfer event}

When enhanced reconnection occurs at the magnetopause, conventional wisdom suggests that two responses in the ionosphere are expected. First, an equatorward protrusion grows onto the ionospheric footprint of the $630 \mathrm{~nm}$ auroral emission associated with the cusp precipitation on a time scale of about 3 min., i.e. Alfvén wave travel time from the reconnection site at the magnetopause to the ionosphere (see Fig.1a,c). This concept was introduced by Cowley (1984), and devel-

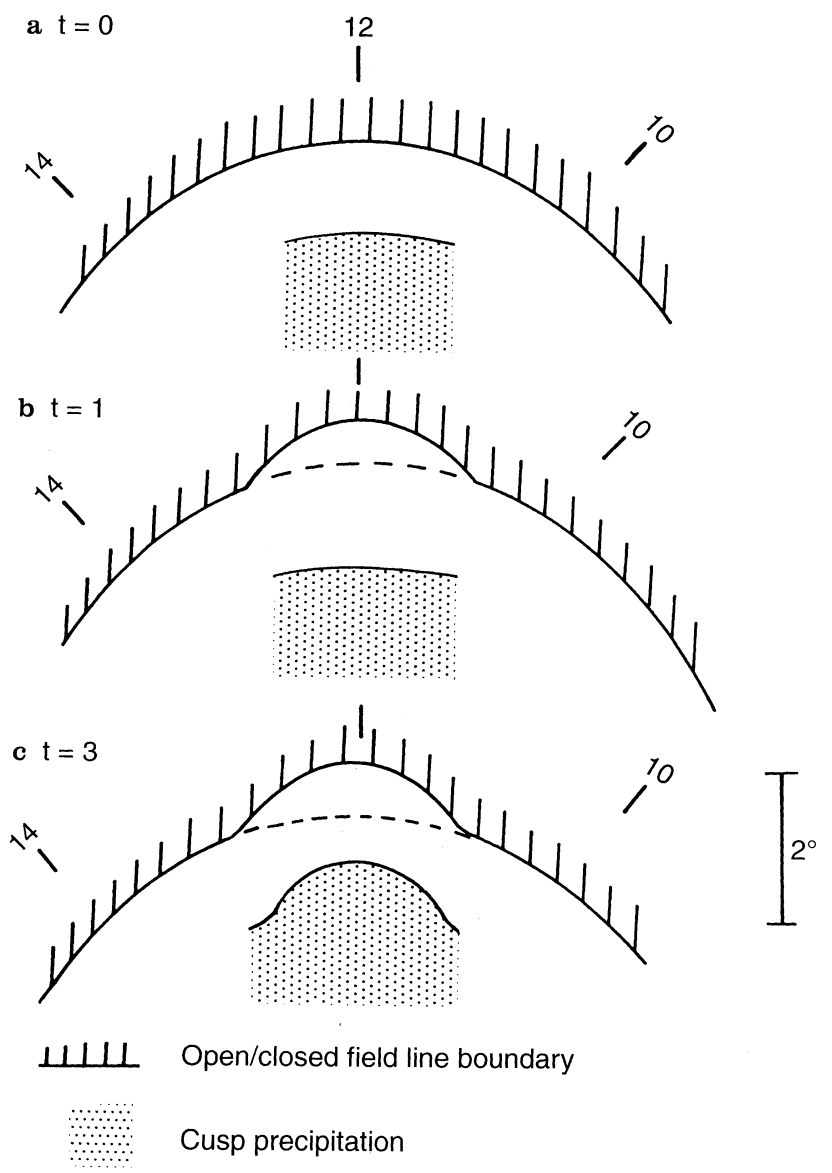

Fig. 1 a-c. Schematic diagram showing the relationship between the ionospheric footprint of the open/closed field line boundary, marked by poleward edge of the $557.7 \mathrm{~nm}$ emission (hatched area), and the location of the $630 \mathrm{~nm}$ emission caused by cusp like energetic particle precipitation (stippled area). a is for 'steady state' conditions, $t=0, \mathbf{b}$ as a but for a few 10s of seconds after reconnection at the equatorial plane has been enhanced, and $\mathbf{c}$ for $t=3$ minutes after enhanced reconnection has occurred in the equatorial plane, and the associated Alfvén wave has arrived at the ionosphere. Assumptions made in constructing this figure are explained in the text. oped further by others (e.g. Southwood 1985, 1987; Freeman and Southwood 1988; Cowley et al., 1991; Cowley and Lockwood, 1992). If reconnection continues, then the protrusion grows with time. If reconnection diminishes, then the $630 \mathrm{~nm}$ emission protrusion relaxes to its original quasi-circular shape.

There is a latitude displacement between the ionospheric location of the open/closed field line boundary and the location of the $630 \mathrm{~nm}$ emission caused by cusp precipitation (e.g. Lockwood and Smith, 1992; Minow, 1995, private communication). The open/closed field line boundary is marked by the poleward limit of a weak $557.7 \mathrm{~nm}$ emission that results from plasmasheet particle precipitation (Fig. 1a). This latitude displacement arises because the most energetic cusp ions take about 3 min to transit from the dayside reconnection site to the ionosphere, during which time the flux tubes convect poleward. The factors affecting the latitude extent of this "auroral dark" region are the distance from the reconnection site on the magnetopause (normally assumed to be the sub-solar point) to the ionosphere, the fieldaligned energy of the ions, and the component of the reconnection electric field that translates into poleward plasma velocity in the ionosphere. Here we have ignored the azimuthal component of motion caused by the $y$ component of the IMF. We note that the above description is accurate only if two assumptions hold. First, there is some background level of reconnection occurring, otherwise the open/closed field line boundary and the equatorward limit of the $630 \mathrm{~nm}$ emission will be collocated. Second, the poleward flow remains constant. In practice, the poleward flow may increase owing to the enhanced reconnection electric field. Therefore the equatorward protrusion will not be as pronounced because the cusp ions will convect further poleward during their transit from the magnetopause, compared with their counterparts immediately before enhanced reconnection started.

Second, the Alfvén wave also carries with it the first information about reconnection at the magnetopause, and the orientation of the sheath magnetic field, a proxy for the IMF. Therefore the first dynamical response in the ionosphere, namely an increase in plasma velocity, would also be expected to be observed at the equatorward edge of the $630 \mathrm{~nm}$ emission region (Southwood, 1987) about 3 min after enhanced reconnection occurred at the magnetopause. This suggestion is supported by the observations of Lockwood et al. (1993) and Pinnock et al. (1993) who show plasma velocity increases associated with FTE signatures occurring within the region of cusp precipitation. Their examples are for occasions when the IMF was likely to have had a significant $y$-component. Thus the effects of field-line tension will force the ionospheric plasma to have a considerable azimuthal component to its motion which makes the events easier to detect.

Important issues remain. For example, it has not yet been determined what controls the magnitude of the equatorward motion of the $630 \mathrm{~nm}$ emission or the increase in ionospheric plasma velocity arising from enhanced reconnection at the magnetopause. In prac- 
tice, both the boundary and the plasma velocity appear to respond to enhanced reconnection (e.g. Lockwood et al., 1993). Also none of the authors cited considers the ionospheric consequences to the region of $557.7 \mathrm{~nm}$ emission, i.e. the open/closed field line boundary, in the first few minutes after enhanced reconnection at the magnetopause.

\section{A revised view of the ionospheric response to flux transfer events}

A re-examination of the Halley PACE radar (Baker et al., 1989) data for 5 February 1994, originally presented by Pinnock et al., (1995), has caused us to question the current description of the ionospheric effects of flux transfer events in the first few minutes after reconnection occurs at the magnetopause. We suggest that the initial ionospheric disturbance associated with an FTE is a velocity perturbation occurring in the vicinity of the open/closed field line boundary, rather than near the equatorward edge of the cusp ion precipitation. Our new observations impose severe constraints upon the time variation of the imposed electric field.

\subsection{High time resolution data}

The HF radar data used in this study are from a sounding pattern that optimises the spatial and temporal resolution capabilities of the radar. The sounding mode alternately samples on a chosen beam whilst sequentially scanning through the other beams. The integration time for each beam is $5 \mathrm{~s}$, giving $10 \mathrm{~s}$ resolution on the chosen beam, which for this study is the beam along the magnetic meridian. Each $160 \mathrm{~s}$, a full scan is completed. The range resolution is $15 \mathrm{~km}$.

The line-of-sight velocity (Vlos) data (Fig. 2) show that there is a region at the furthest ranges with considerable velocity variability between adjacent ranges and between consecutive $10 \mathrm{~s}$ samples from the same range. This is especially clear between 1500-1600 UT. The power spectra from individual ranges for this region have broad $\left(>200 \mathrm{~m} \mathrm{~s}^{-1}\right.$ ) Doppler spectral widths, the principal characteristic of the ionospheric footprint of cusp precipitation (Baker et al., 1995; Rodger et al., 1995). More equatorward, a second region is observed where the Vlos measurements are more consistent from one range to the next and from one sample to the next. The corresponding power spectra have narrow Doppler spectral widths $\left(<150 \mathrm{~m}^{-1}\right)$, and therefore this region is not the ionospheric footprint of cusp precipitation (Baker et al., 1995). On this occasion, we observe scatter several degrees equatorward of the ionospheric signature of cusp precipitation. This is rare. We have not yet determined under what circumstances it occurs, and thus detailed examination of other examples is not yet possible.

There are many short-lived Vlos enhancements, first seen 100-200 km equatorward of the region to where the

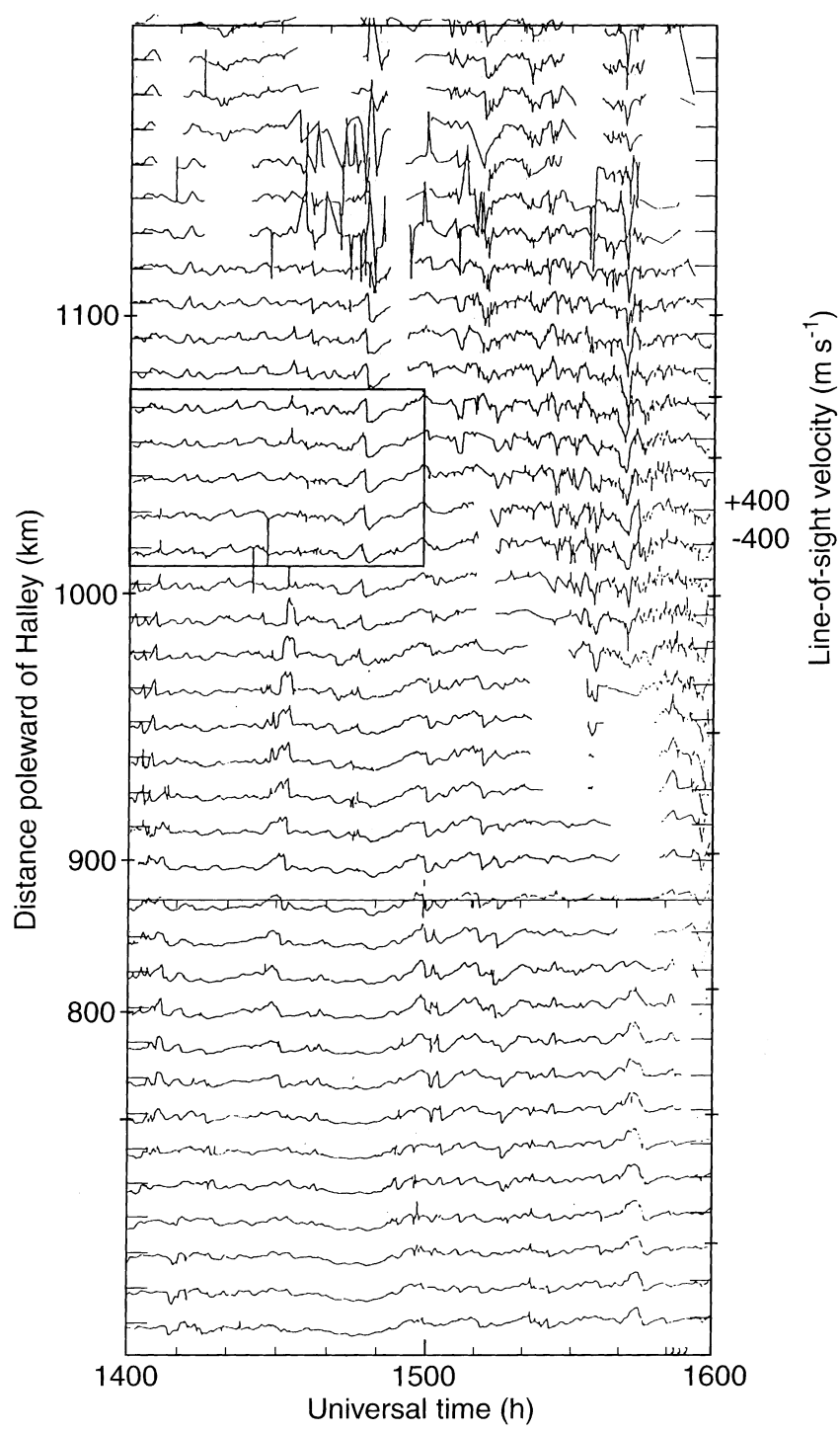

Fig. 2. The line-of-sight velocity determined at $15 \mathrm{~km}$ range intervals from 700-1200 km poleward of Halley for the period 1400-1600 UT on 5 February 1994. The region of highly variable line-of-sight velocity which moves progressively equatorward is where cusp precipitation is occurring. This is especially clear above $\sim 1000 \mathrm{~km}$ range after 1500 UT. The data in the boxed area are reproduced in Fig. 3 on an expanded scale

cusp precipitation maps. The rise in speed appears long in comparison with the fall in speed. These events move poleward with time, a feature more easily seen in Fig.1 of Pinnock et al. (1995). The largest amplitude Vlos variations occur within 3-5 range gates $(45-75 \mathrm{~km})$ of the most equatorward limit where the variation can be identified i.e. well equatorward of the region showing the highly variable Vlos measurements. Similar observations have been made with EISCAT in the early afternoon sector by Moen et al., (1996), but these authors did not focus upon the equatorward extent of the velocity transients. Optical observations made from Svalbard do not show any evidence of such large or rapid equatorward motion of the $630 \mathrm{~nm}$ cusp precipitation region, e.g. Sandholt et al. (1994). 
A further critical factor is that the equatorward edge of the broad spectral width region (i.e. cusp precipitation) often moves equatorward by up to $50 \mathrm{~km}$ immediately after velocity transients reach this location. Examples occur at 1505, 1510 and 1545 UT, which can be readily seen in Fig. 1 of Pinnock et al. (1995). This is what is predicted by previous work (e.g. Southwood, 1987).

Pinnock et al. (1995) conclude that the Vlos signatures of these events are identical to the ionospheric signature of FTEs described by Pinnock et al. (1991; 1993), when allowance is made for the 3 min resolution of the full scan data. Occasionally events are observed well equatorward of the cusp precipitation region, but do not propagate poleward into it. An example occurs at $\sim 1432$ UT between $900-1000 \mathrm{~km}$ poleward of Halley. For these occasions, we believe that the disturbance drifts azimuthally out of the beam used for these high resolution measurements.

In Fig. 3, we present a subset of Fig. 2 to demonstrate the precise character of the rising and falling Vlos signatures. Each event has the characteristics of a "shark's fin", namely an exponential rise followed by an exponential fall in the value of Vlos. We have compared exponential functions of the form $V=V_{o}\left(1-\mathrm{e}^{-\mathrm{t} / \mathrm{T}}\right)$ to each of the events labelled $1-3$ on Fig. 3. These events were selected to represent a range of velocity variations and durations.

Figure $4 \mathrm{a}$ shows the average Vlos for the five ranges shown in Fig. 3 for the event that starts about 1416 UT. The data have been averaged by determining the start time of the event in each range, and designating this time as $t=0$. Data from each subsequent time step is then averaged. The typical uncertainty of the averaged Vlos is $\sim 20 \mathrm{~ms}^{-1}$. Using this technique, the poleward motion of

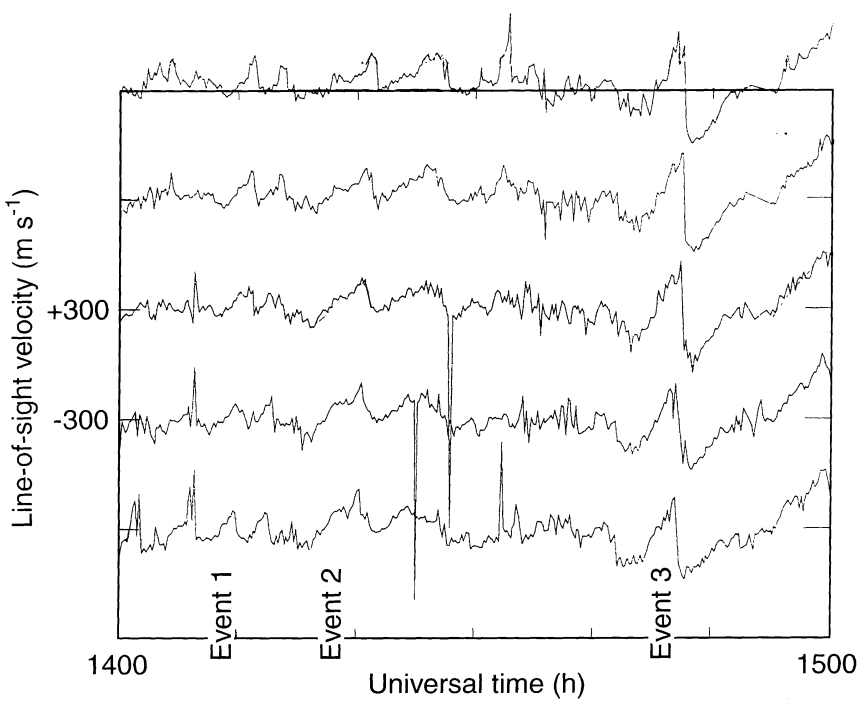

Fig. 3. Five contiguous ranges of the line-of-sight velocity for the interval 1400-1500 UT on 5 February 1994. The three events marked are studied in further detail, together with the rapid fall in velocity immediately following event 3 . There are two very large negative velocity spikes at 1425 and 1428 UT. We believe that these are caused by interference, and are not geophysically significant.
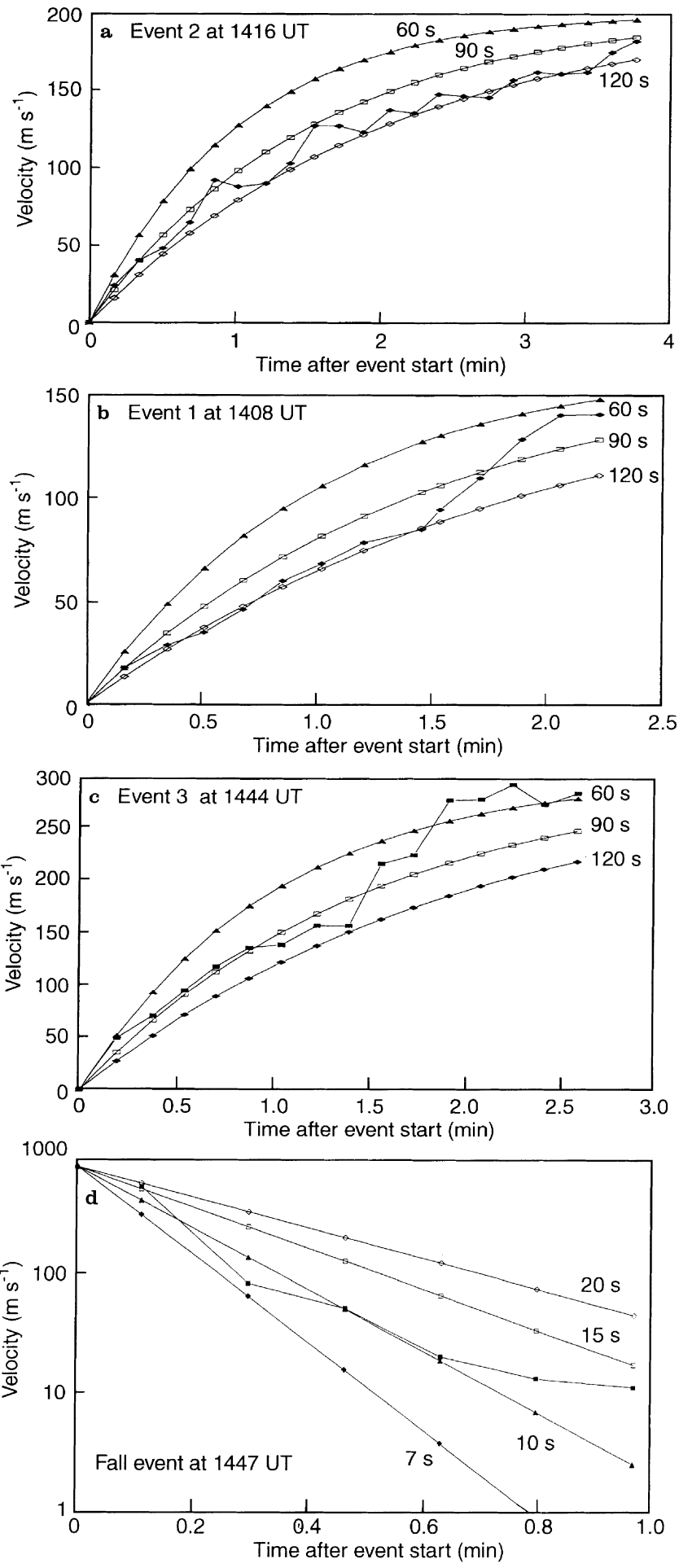

Fig. 4a-d. Line-of-sight velocity measurements, averaged over the 5 range gates shown in Fig.3, as a function of time since the start of the event. The way in which the line-of-sight velocity measurements have been averaged is described in the text. Exponential curves of the form $V=V_{o}\left(1-\mathrm{e}^{-t / T}\right)$ are shown using three time constants, $T=60,90$ and $120 \mathrm{~s}$. a event 2 starting at $1416 \mathrm{UT}$, b event 1 starting at $1408 \mathrm{UT}$ and $\mathbf{c}$ event 3 starting at 1444 UT. d Falling line-of-sight velocity measurement for interval immediately following event 3 . Curves derived using the time constant curve $V=V_{o}\left(\mathrm{e}^{-t / T}\right)$ with $T=7,10,15$ and $20 \mathrm{~s}$ are shown. 
the event 2 across these five ranges is $\sim 1.5 \mathrm{~km} \mathrm{~s}^{-1}$, whereas the plasma motion varies between $\sim 200$ and $500 \mathrm{~ms}^{-1}$ over the same interval (Fig. 3). The difference between the phase and plasma motion can be reconciled if the disturbance front of the event is tilted with respect to the perpendicular to the observing direction.

Exponential curves with time constants $(T)$ of 60,90 and $120 \mathrm{~s}$ are also shown as Fig. 4a. These suggest that a time constant of $\sim 100 \mathrm{~s}$ is appropriate. The data for events 1 and 3 have been treated in the same way (Fig. $4 \mathrm{~b}, \mathrm{c}$ ). Again a time constant of $\sim 100 \mathrm{~s}$ is consistent with the observations, though we note that both of these events may comprise the superposition of two events lasting 1-1.5 min. The phase speed for event $1(1408$ UT) is about $0.8 \mathrm{~km} \mathrm{~s}^{-1}$ whereas for event 3 (1444 UT) the event occurs simultaneously in all ranges suggesting a phase speed $>7.5 \mathrm{~km} \mathrm{~s}^{-1}$.

We have adopted a similar approach when considering the falling event that closes event 3 (see Fig. 3). On this occasion (Fig. 4d), we use the form $V=V_{o}\left(\mathrm{e}^{-t / T}\right)$. We have used a range of time constants ranging from 5 to $20 \mathrm{~s}$, and plotted both these curves and the observation on a logarithmic scale. The time constant that corresponds best to the data is about $10 \mathrm{~s}$, but our measurements are at $10 \mathrm{~s}$ intervals with a $5 \mathrm{~s}$ integration period. Therefore, there is considerable uncertainty in this time constant.

\section{Implications and interpretation of the new observations}

The ionospheric effect of the Vlos changes is seen up to $200 \mathrm{~km}$ equatorward of the location of the cusp precipitation. We suggest that this separation comprises two parts. First, the distance between the open/closed field line boundary and the cusp precipitation region. Over this study interval, the poleward speed of the plasma varies between about 400 and $800 \mathrm{~m} \mathrm{~s}^{-1}$. If the time for the energetic ions to travel from the magnetopause reconnection site to the ionosphere is 3 minutes, then they will arrive between 70 and $150 \mathrm{~km}$ poleward of the open/closed field line boundary. The second component arises because the ionosphere is incompressible. Figure 2 indicates that the largest velocity variations are within $3-5$ range gates $(\sim 45-75$ $\mathrm{km}$ ) of the equatorward limit of the velocity perturbations. We suggest that where the largest velocity variations occur marks the ionospheric footprint of the open/closed field line boundary, and owing to flux continuity the velocity variations can be observed somewhat equatorward of this boundary. The combined distances from these two elements is $115-225 \mathrm{~km}$, very close to the observations. Therefore, we suggest that the Vlos variations are caused by a process associated with the open/closed field line boundary. Cowley and Lockwood (1992) discuss the effects of enhanced reconnection on the open/closed field line boundary but do not identify clearly either the fieldaligned current carriers or the separation between the open/closed field line boundary and the ionospheric footprint of cusp ion precipitation.
To accelerate plasma near the ionospheric footprint of the open/closed field line boundary, an additional electric field is required. We suggest that this may be achieved by the establishment of a field-aligned current caused by the outflow from the magnetosphere of energetic magnetospheric particles. It is well accepted that during reconnection magnetosheath particles enter the magnetosphere, one of their ionospheric signatures being the $630 \mathrm{~nm}$ cusp emission. At the same time, magnetospheric electrons can 'escape' into the sheath (e.g. Gosling et al., 1990). The characteristic energy of the magnetospheric electrons near $L=9$ in the equatorial plane, a typical value of the last closed flux tube on the dayside, is $\sim$ few $\mathrm{keV}$. Indeed it is the part of this population with low pitch angles that is responsible for the weak $557.7 \mathrm{~nm}$ emission (Fig. 1). As the bounce time of such particles is short ( $\sim$ a few seconds), one immediate consequence of enhanced reconnection is that the flux of $\mathrm{keV}$ electrons causing the $557.7 \mathrm{~nm}$ emission will be lost through the magnetopause to the magnetosheath. Thus, the dark region of no emission will grow an equatorward protrusion. This is the first prediction of our new description, and is shown schematically in Fig. 1b. High-time resolution, sensitive allsky imager data will be required to observe such events. At oblique incidence, the finite height emission profile will make it impossible to detect the "dark region". Therefore to be observed, the dark equatorward protrusion must be close to the observing station which obviously must be in darkness. Hence South Pole station and Svalbard are key locations to search for these events, being well-instrumented sites frequently under the ionospheric footprint of the cusp and in darkness at magnetic noon in winter.

The energetic magnetospheric electron population will be lost to the magnetosheath very quickly $(\sim$ a few bounce periods) after the flux tube is involved in reconnection. It is necessary to maintain change neutrality. Onsager et al. (1995) have noted the importance of the ionospheric source of electrons in maintaining charge neutrality. We also noted that recently small fluxes of very energetic ions $(\sim 200 \mathrm{keV})$ have been detected by the POLAR satellite on open cusp-like field lines (Spence, private communication). These particles too may have a role to play in maintaining charge neutrality. At mid-altitudes (20,000 km), Burch (1985) suggests that charge neutrality is maintained by a precise balance between the number of energetic ions and electrons of sheath-like energies. However he does not consider the situation in the critical region discussed here, namely the open/closed field line boundary. In summary, we consider that the way in which charge neutrality is maintained on recently-opened flux tubes is an outstanding question.

Associated with the enhanced plasma motion near the ionospheric footprint of the open/closed field line boundary will be a field-aligned current system. The energetic electrons being lost into the sheath could form part of the current system but exactly how the current is carried in the magnetosphere remains an unresolved issue too. Data from the POLAR satellite and any 
reflight of CLUSTER should be able to address this matter.

One further consequence, which is probably of minor importance, is that during the $3 \mathrm{~min}$ period between reconnection occurring and the sheath particles arriving in the ionosphere, energetic ring current protons (electrons) drifting westward (eastward) in the outermost flux tubes of the magnetosphere under gradient and curvature drift will encounter the equatorward protrusion of the open/closed field line boundary. Thus, they will be lost from the magnetosphere, setting up a small upward field-aligned current from the western end (proton loss), and a downward field aligned current (electron loss) at the eastern end of the protrusion. The electric field associated with these currents will tend to decelerate the poleward plasma in the region between the two currents.

The time constants of the rise and fall in the line-ofsight velocity are very approximately 100 and $10 \mathrm{~s}$ respectively. We cannot explain either time scale but point out that the rise time is very long compared with the electron bounce time. Hence the rise time may be controlled by processes associated with reconnection.

As a final comment, we note that recent studies of travelling convection vortices (TCVs) (e.g. Yahnin and Moretto, 1996) show that events appear to maximise in their magnetic field variations $1-2^{\mathrm{o}}$ equatorward of the cusp precipitation, and indicate that many TCVs are field-aligned current systems that are evolving very rapidly in space and time. Therefore, some TCVs may be another ionospheric manifestation of the proposed new current system.

\section{Conclusions}

We have provided new observations of the ionospheric signatures of flux transfer events using high-time resolution measurements from the Halley PACE radar. We find that they are not consistent with current description of FTEs (e.g. Southwood, 1987) in two important ways. Events occur first 100-200 km equatorward of the ionospheric footprint of cusp precipitation, and their maximum velocity variations occur very close to where these events are first observed. We suggest that the velocity variations are initiated in the vicinity of the ionospheric footprint of the open/closed field line boundary. This is contrary to current model descriptions which place both effects at the ionospheric footprint of cusp sheath-like precipitation. We suggest that the observed velocity variations are caused by an electric field that is in addition to that carried by the Alfvén wave associated with enhanced reconnection that maps to the equatorward edge of the cusp precipitation. The rise time of the new electric field is $\sim 100 \mathrm{~s}$, and its fall time is $\sim 10 \mathrm{~s}$.

A hypothesis for these new observations is proposed. It involves the rapid outflow of magnetospheric electrons from the flux tubes that have just undergone reconnection, which establishes a field-aligned current very rapidly in the vicinity of the open/closed field line boundary. This new hypothesis indicates that there should be an immediate equatorward protrusion of the region of auroral darkness that occurs between the open/closed field line boundary and the cusp precipitation which should be detectable with good ground-based optical observations. Further, the proposed new fieldaligned current should be detectable by ISTP spacecraft.

Acknowledgements. We are grateful to Dr M. P. Freeman and to the referees for helpful comments and suggestions.

Topical Editor D. Alcaydé thanks C. T. Russell and another referee for their help in evaluating this paper.

\section{References}

Baker, K. B., R. A. Greenwald, J. M. Ruohoniemi, J. R. Dudeney, M. Pinnock, N. Mattin, and J. M. Leonard, PACE, Polar Anglo-American Conjugate Experiment, Eos, 70, 785, 1989.

Baker, K. B., J. R. Dudeney, R. A. Greenwald, M. Pinnock, P. T. Newell, A. S. Rodger, N. Mattin, and C.-I. Meng, HF radar signatures of the cusp and low latitude boundary layer, $J$. Geophys. Res., 100, 7671, 1995.

Burch J. L., Quasi-neutrality of the cusp, Geophys. Res. Lett., 17, 469, 1985.

Cowley, S. W. H., Evidence for the occurrence and importance of reconnection between the Earth's magnetic field and the interplanetary field, in Magnetic reconnection in space and laboratory plasma, Geophys. Monograph Ser., 30, Ed. E W Hones, Jnr, AGU, Washington DC, USA, 1984.

Cowley S. W. H., and M. Lockwood, Excitation and decay of solarwind driven flows in the magnetosphere-ionosphere system, Ann. Geophysicae, 10, 103, 1992.

Cowley S. W. H., M. P. Freeman, M. Lockwood, and M. F. Smith, The ionospheric signature of flux transfer events, in CLUSTER - dayside polar cusp, Eur. Space Agency Spec. Publ., SP-330, $105,1991$.

Dungey, J. W., Interplanetary field and the auroral zones, Phys. Rev. Lett., 6, 47, 1961.

Freeman, M. P., and D. J. Southwood, The effect of magnetospheric erosion on mid- and high-latitude ionospheric flows, Planet. Space Sci., 36, 509, 1988.

Goertz C. K., E. Neilsen, A. Korth, K. H. Glassmeier, C. Haldoupis, P. Hoeg, and D. Hayward, Observations of a possible ground signature of flux transfer events, J. Geophys. Res., 90, 4069, 1985.

Gosling, J. T., M. F. Thomsen, S. J. Bame, T. G. Onsager, and C. T. Russell, The electron edge of the low latitude boundary layer during accelerated flow events, Geophys. Res. Lett., 17, 1833, 1990.

Greenwald R. A., K. B. Baker, J. R. Dudeney, M. Pinnock, T. B. Jones, E. C. Thomas, J-P. Villain, J-C. Cerisier, C. Senior, C. Hanuise, R. D. Hunsucker, G. Sofko, J. Koehler, E. Nielsen, R. Pellinen, A. D. M. Walker, N. Sato, and H. Yamagishi, DARN/ SuperDARN: a global view of the dynamics of high latitude convection, Space Sci Rev, 71, 761, 1995.

Kan, J. R., A theory of patchy and intermittent reconnection for magnetospheric flux transfer events, J. Geophys. Res., 93, 5613, 1988.

Lanzerotti, L. J., A. Wolfe, N. Trevedi, C. G. Maclennan, and L. V. Medford, Magnetic impulse events at high latitude: magnetopause and boundary layer plasma processes, J. Geophys. Res., 95, 97, 1990.

Lockwood, M., and M. F. Smith, The variation of reconnection rate at the dayside magnetopause and cusp ion precipitation, $J$. Geophys. Res., 94, 12841, 1992.

Lockwood, M., S. W. H. Cowley, P. E. Sandholt, and R. P. Lepping, The ionospheric signatures of flux transfer events and solar wind dynamic pressure changes, J. Geophys. Res., 95, 17113, 1990. 
Lockwood, M., W. F. Denig, A. D. Farmer, V. N. Davda, S. W. H. Cowley, and H. Lühr, Ionospheric signatures of pulsed reconnection at the Earth's magnetopause, Nature, 361, 424, 1993.

Lockwood, M., S. W. H. Cowley, and M. F. Smith, Comment on "By fluctuations in the magnetosheath and azimuthal flow velocity transients in the dayside ionosphere" by Newell and Sibeck, Geophys. Res. Lett., 21, 1819, 1994.

Moen, J., M. Lockwood, P. E. Sandholt, U. P. Lovhaug, W. F. Denig, A. P. van Eyken, and A. Egeland, Variability of dayside high latitude convection associated with a sequence of auroral transients, J. Atmos. Terr. Phys., 58, 85, 1996.

Newell, P. T., and D. G. Sibeck, Upper limits on the contribution of FTEs to ionospheric convection, Geophys. Res. Lett., 20, 2829, 1993.

Onsager, T. G., S-W Chang, J. D. Perez, J. B. Austin, and L. X. Janoo, Low altitude observations and modeling of quasi-steady magnetopause reconnection, J. Geophys. Res., 100, 11831, 1995.

Pinnock, M., A. S. Rodger, J. R. Dudeney, R. A. Greenwald, K. B. Baker, and J. M. Ruohoniemi, An ionospheric signature of possible enhanced field merging on the dayside magnetopause, J. Atmos. Terr. Phys., 53, 201, 1991.

Pinnock, M., A. S. Rodger, J. R. Dudeney, K. B. Baker, R. A. Greenwald, and M. Greenspan, Observations of an enhanced convection channel in the cusp ionosphere, J. Geophys. Res., 98, 3767, 1993.

Pinnock, M., A. S. Rodger, J. R. Dudeney, F. Rich and K. Baker, High spatial and temporal observations of the ionospheric cusp, Ann. Geophysicae, 13, 919, 1995.

Rijnbeck, R. P., S. W. H. Cowley, D. J. Southwood, and C. T. Russell, A survey of dayside flux transfer events observed by the ISEE 1 and 2 magnetometers, J. Geophys. Res., 89, 786, 1984.
Rodger, A. S., S. B. Mende, T. J. Rosenberg, and K. B. Baker, Simultaneous optical and HF radar observations of the ionospheric cusp, Geophys. Res. Lett., 22, 2045, 1995.

Russell, C. T. and R. C. Elphic, ISEE observations of flux transfer events on the dayside magnetopause, Geophys. Res. Lett, 6, 33, 1979.

Sandholt, P. E., M. Lockwood, B. Lybbek, and A. D. Farmer, Auroral bright spot sequence near 1400 MLT: coordinated optical and ion drift observations, J. Geophys. Res., 95, 21095, 1990.

Sandholt, P. E., C. J. Farrugia, L. F. Burluga, J. A. Holtet, J. Moen, B. Lybbek, B. Jacobsen, D. Opsvik, A. Egeland, R. Lepping, A. J. Lazurus, T. Hansen, A. Brekke, and E. FriisChristensen, Cusp/cleft auroral activity in relation to solar wind dynamic pressure, interplanetary magnetic field $\mathrm{Bz}$ and $\mathrm{By}, J$. Geophys. Res., 99, 17323, 1994.

Southwood, D. J., Theoretical aspects of ionosphere-magnetosphere-solar wind coupling, Adv. Space Res., 5, (4), 1985.

Southwood, D. J., The ionospheric signature of flux transfer events, J. Geophys. Res., 92, 3207, 1987.

Villain, J-P., R. A. Greenwald, and J. F. Vickrey, HF ray-tracing at high latitudes using measured electron density distributions, Radio Sci., 19, 359, 1984.

Yahnin, A., and T. Moretto, Travelling convection vortices in the ionosphere map to the central plasma sheet, Ann. Geophysicae, 14, 1025, 1996. 